\title{
Total Correction of Tetralogy of Fallot
}

\author{
Review of Ten Years' Experience
}

\author{
BERNARD S. GOLDMAN*, WILLIAM T. MUSTARD, AND GEORGE S. TRUSLER \\ From the Department of Surgery, Hospital for Sick Children and the University of Toronto, Toronto, Ontario, Canada
}

Total physiological correction of the tetralogy of Fallot can now be achieved with an acceptable mortality rate and with gratifying clinical results (Kirklin et al., 1965; Malm et al., 1966). The current success with surgical management of this form of cyanotic heart disease has evolved in this, as well as many other centres, through three fairly distinct periods. Before 1957, a few desperately ill infants and children underwent rapid closure of the ventricular septal defect with forceful dilatation of the stenotic pulmonary valve while supported by early cardiac bypass pumps, using either autogenous or heterologous (monkey-lung) oxygenation (Mustard and Thomson, 1957). This phase coincided with other bold attempts at total correction with hypothermia (Scott, Collins, and Foster, 1954) and with homologous cardiopulmonary support (Lillehei et al., 1955).

Rapid improvements in surgical technique and circulatory support occurred in the developmental period between 1957 and 1962. During this time we used varied forms of heart-lung bypass apparatus, and as the anatomy of the defects became familiar the surgical repair became more standardized and skilful. The recent era, from 1963, has witnessed the culmination of earlier surgical efforts, and this, combined with more physiological perfusions, and better post-operative management, has yielded the presently acceptable mortality rate for total haemodynamic correction.

\section{CONDUCT OF Perfusion}

We routinely use the disc oxygenator for these perfusions. Fresh heparinized blood is used to prime the pump-oxygenator; for larger children ( $>10 \mathrm{~kg}$.) we have recently been using fresh reconstituted acid-citratedextrose solution blood titrated to a normal $p \mathrm{H}$ with

\footnotetext{
Received December 5, 1967.

$\star$ Present address: Cardiovascular Unit, Toronto General Hospital, Toronto, Ontario, Canada.
}

THAM (Tris buffer: 3-OH amino-methane). Haemodilution to $20 \mathrm{ml} . / \mathrm{kg}$. body weight with 5 per cent dextrose in $\mathbf{0 . 4 5}$ per cent NS is employed, and mannitol ( $25 \%$ solution) is added to the pump after the onset of bypass. Blood losses and extracardiac suction losses are replaced intravenously with whole blood.

Heparin is given $(1.5 \mathrm{mg} . / \mathrm{kg}$. body weight) before connexion with the pump, and repeated doses of 0.75 mg. $/ \mathrm{kg}$. are given for each hour of perfusion. Neutralization with protamine sulphate is accomplished at the end of perfusion with 1.5 times the amount of injected heparin (including the heparinized blood in the pump). A blood sample for protamine titration may reveal the need for further protamine administration.

An infusion of aminocaproic acid (epsilon-aminocaproic-acid) is begun on all cyanotic patients undergoing perfusion at the time of sternotomy. An initial dose of $70 \mathrm{ml}$. $/ \mathrm{kg}$. is given over the first hour, with $15 \mathrm{ml}$. per hour thereafter for 12 to 24 hours. This has decreased the incidence of post-operative bleeding.

Flow rates are calculated at $2 \cdot 41 . / \mathrm{m}^{2} / \mathrm{min}$. and core cooling to $31^{\circ} \mathrm{C}$. is employed. Because of the perfusion loss into the huge collateral pulmonary vascular bed, the temperature may be lowered (to $25^{\circ} \mathrm{C}$.) to decrease the intracardiac return by allowing reduction of the flow rate. Periods of aortic clamp-off are limited to 3-5 minutes to protect myocardial function.

\section{CURRent Surgical Management}

The architecture of the right ventricular outflow tract is studied before operation in all patients by selective angiocardiography. The heart is approached through a median sternotomy, care being taken to avoid entry into either pleural space when possible. Connexions are made for cardiopulmonary bypass and attention is paid to securing a prior Blalock-Taussig anastomosis if present and functioning; the shunt is clamped just before perfusion. A functioning Potts' anastomosis is approached through the left main pulmonary artery under conditions of total circulatory arrest at an oesophageal temperature of $15^{\circ} \mathrm{C}$. (Kirklin et al., 1960). In all instances a vent is inserted into the apex of the left ventricle at the start of the perfusion. 
The incision in the right ventricle is made in the direction indicated by the need for outflow reconstruction or by the presence of significant coronary vessels crossing the infundibulum. We have not adhered routinely to the transverse ventriculotomy (Gerbode et al., 1964); it is more important that the incision be small, that it avoid papillary muscles, and that the parietal and septal bands of the crista supraventricularis be freed early to allow better visualization. The ventricular septal defect, typically large and in close proximity to the annulus of the overriding aorta, is closed with a patch of woven Dacron, using interrupted mattress sutures. The stenotic pulmonary valve is inverted from below, or approached through a standard pulmonary arteriotomy. Sufficient resection of the hypertrophic fibro-muscular bands obstructing the outflow tract is performed to permit free passage of a $16-18 \mathrm{~mm}$. Hegar dilator to the bifurcation of the pulmonary artery. Care must be taken to avoid creating a ventricular septal defect or entrance into an aortic sinus. Reconstruction of the infundibulum with a roof of pericardium is occasionally necessary. It is sometimes necessary to insert a pericardial patch across a hypoplastic pulmonary valve ring, even to the bifurcation, if the main pulmonary artery is itself small. We will accept a residual gradient of $30-40 \mathrm{~mm}$. $\mathrm{Hg}$ across the outflow tract.

Pacemaker wires are sutured to the myocardium if there is any evidence of altered AV conduction.

\section{Management of Post-operative Period}

A nasotracheal tube is left in place for 12-72 hours, and the patient is ventilated with the Engström volumecycled respirator to obtain maximal oxygenation and to decrease the work of breathing. At the end of this period, the child is weaned from ventilatory support or a tracheostomy is performed.

The right atrial pressure is carefully monitored with deliberate overtransfusion to maintain pressures of $18-20 \mathrm{~cm} . \mathrm{H}_{2} \mathrm{O}$. This high filling pressure is essential to the non-compliant right ventricle, especially after outflow reconstruction (Kirklin et al., 1960). Isoprenaline has been valuable in those patients manifesting a low cardiac output state, as well as attention to the arterial blood gases, correction of $p H$ deficits with sodium bicarbonate or THAM, and maintenance of adequate urinary outputs with increments of mannitol. All patients are routinely digitalized if the serum potassium levels are adequate.

\section{Clinical Experience}

In the 10-year period from January 1,1957 , to December 31, 1966, 188 children have undergone total correction for tetralogy of Fallot at the Hospital for Sick Children, Toronto. This series does not include children with pulmonary stenosis and interventricular septal defects. Fifty-two children were classed as acyanotic (atypical tetralogy) while the remaining 136 were cyanotic. The distinction was based on the clinical status and haemodynamic findings at cardiac catheterization, and is reflected in the mean resting arterial oxygen saturation and haemoglobin concentration (Table I).

TABLE I

CLINICAL STATUS OF 188 CHILDREN WITH TETRALOGY OF FALLOT

\begin{tabular}{l|c|c|c}
\hline & Acyanotic & Cyanotic & Total \\
\hline $\begin{array}{ll}\text { No. of patients } \\
\text { Mean arterial oxygen }\end{array}$ & 52 & 136 & 188 \\
$\begin{array}{l}\text { saturation (\%) } \\
\text { Mean Hb concentration }\end{array}$ & $92 \cdot 7$ & $79 \cdot 2$ & \\
(g./100 ml.) & 13.8 & $18 \cdot 1$ & \\
\hline
\end{tabular}

Note: The ages ranged from 1 to 16 years; there were 18 children below the age of 5 years, who were operated upon early in the series.

\section{RESULTS}

The hospital and late mortality from total correction is presented in Table II. The initial experience (1957-1962) is presented arbitrarily as a cumulative result, because of the developmental quality of this period, and to contrast with the improved results of the recent years (1963-1966).

TABLE JI

MORTALITY FROM TOTAL CORRECTION OF TETRALOGY OF FALLOT

\begin{tabular}{r|c|c|c}
\hline & \multicolumn{3}{|c}{ Mortality } \\
\cline { 2 - 3 } & Total & $\begin{array}{c}\text { Acyan- } \\
\text { otic (\%) }\end{array}$ & $\begin{array}{c}\text { Cyan- } \\
\text { otic (\%) }\end{array}$ \\
\hline 1: Early group_1957-62 & 72 & 29 & 39 \\
2: Current group-1963 & 30 & 0 & 31 \\
1964 & 27 & 28 & 20 \\
1965 & 31 & 0 & 13 \\
1966 & 28 & 0 & 14 \\
\hline
\end{tabular}

Influence of an Earlier Palliative Procedure. It is our practice to perform some form of palliation in those cyanotic children who are symptomatic from the effects of hypoxia below the age of 5 years, in anticipation of a later total correction. Three patients had undergone closed resection of the infundibulum (Brock and Campbell, 1950; Brock, 1957): two of these children died after subsequent total correction.

Three patients had an anastomosis created between the left main pulmonary artery and the descending thoracic aorta, 10-13 years earlier (Potts, Smith, and Gibson, 1946). Two died after total correction. In the third child, the anastomosis could not be located, and thus the attempted total correction was abandoned. We have abandoned both the Brock procedure and the Potts' anastomosis.

Seventy-nine subclavian-pulmonary artery anastomoses had been constructed up to 14 years earlier (Blalock and Taussig, 1945). Eight patients required two shunts each; either bilateral BlalockTaussig (6 patients) or a Potts' plus Blalock (2 
patients). Only 47 of these systemic-pulmonary artery shunts (Blalock + Potts') were open (of 82 total). Of the 73 patients with Blalock anastomoses only, 30 died after total correction, a mortality of 41 per cent; of the early group (1957-1962), 9 patients died after total correction out of 19 with prior Blalocks. In the later group (1963-1966), of 54 patients with prior subclavian-pulmonary artery shunts, 21 did not survive. The relative increase in the number of patients with shunts coming for total correction in the recent series represents the harvest of children palliated up to 14 years earlier for symptoms of severe hypoxia.

The mortality of patients who did not require prior palliative surgery was significantly lower due to the inclusion of the acyanotic group. Furthermore, patients with a prior systemic-pulmonary shunt, which was open and functioning at the time of total correction, had a lower mortality rate (32\%) than those patients in whom the shunt had failed $(62 \%)$.

Influence on Mortality of the Extent of Outflow Reconstruction. Reconstruction of the pulmonary outflow tract with insertion of a pericardial gusset or a prosthetic roof, after sharp resection of obstructing muscle, was thought necessary in 109 patients $(58 \%)$. This was confined to the infundibulum in 60 patients; to the main pulmonary artery in 9 patients; and extended across the valve annulus in 40 patients.

Certain facts are readily noted from the data of the later 116 patients (1963-1966) and are summarized in Table III. Primary closure of the ventriculotomy without the need for an enlarging patch was accomplished in 70 patients; only 9 of these died. However, of 16 patients who required patch reconstruction across the pulmonary valve annulus to the bifurcation of the main pulmonary artery, 8 patients failed to survive. The influence of extensive reconstruction on mortality is thus apparent. The insertion of a patch into the pulmonary artery alone did not seem to influence the mortality.

Other Factors Influencing Mortality. Massive operative and post-operative bleeding contributed to the death of 9 patients in the last 116. The haemorrhagic diathesis attending upon open-heart correction in cyanotic, polycythaemic patients is well recognized. This problem has all but been eliminated from our recent series by the routine prophylactic use of epsilon-amino-caproic acid. Meticulous haemostasis, haemodilution perfusions, the liberal use of pro-coagulant substances and
TABLE III

EXTENT OF RECONSTRUCTION OF THE OUTFLOW TRACT CORRELATED WITH SURVIVAL IN 46 OF THE LATER 116 PATIENTS (1963-1966)

\begin{tabular}{l|c|c|c}
\hline & $\begin{array}{c}\text { No. } \\
\text { operated } \\
\text { on }\end{array}$ & \multicolumn{2}{|c|}{ Mortality } \\
\cline { 4 - 5 } & No. & $\%$ \\
\hline $\begin{array}{l}\text { Patch confined to pulmonary artery } \\
\text { Patch confined to right ventricular }\end{array}$ & 8 & 1 & 13 \\
$\begin{array}{c}\text { infundibulum } \\
\text { Patch across pulmonary valve annulus } \\
\text { to bifurcation of pulmonary artery }\end{array}$ & 22 & 5 & 23 \\
\hline
\end{tabular}

fresh whole blood are, of course, invaluable in this respect.

Although the incidence of heart block has decreased in recent years, this remains a hazard in the repair of the interventricular septal defect. Temporary AV dissociation due to myocardial hypoxia, hypothermia, and operative trauma are not uncommon and have required the insertion of myocardial wires for short-term post-operative pacing. Corticosteroids may be beneficial in the resolution of the block. In some instances the block persists and is clearly related to damage to the conducting bundle. Permanent heart block was noted in 5 children in the initial group ( 72 patients). In the subsequent 116 patients, 7 had persisting complete heart block; 2 were discharged, 1 with adequate ventricular rate and normal exercise tolerance, 1 other with an implanted electronic pacemaker. Of the remaining 5 children in this latter group, 2 died of arrhythmias during the post-operative period, and in 3 children the block was a complicating factor in death from associated causes.

A low cardiac output state has been noted after total correction for tetralogy of Fallot. Numerous factors have been implicated: myocardial dysfunction from coronary air embolism, prolonged aortic clamp-off, or coronary artery ligation, a persistently open ventricular septal defect or shunt, or an inefficient right ventricle after extensive resections or reconstruction with pulmonary valve insufficiency. The syndrome is perpetuated by progressive respiratory failure and refractory metabolic acidosis. We have encountered this syndrome in 16 patients (in 4 instances pulmonary oedema appeared to be related to a hypoplastic left ventricle).

These patients have lately responded to infusions of isoprenaline, mechanical ventilatory assistance, maintenance of a high right atrial pressure, and vigorous correction of the acidosis. This state, of course, is often concurrent with other major causes of death such as haemorrhage, heart block, etc.

As in any major operative procedure, post-operative sepsis accounts for a certain morbidity and 
mortality. There were 3 cases of septicaemia and 3 of mediastinitis that were fatal in outcome.

\section{COMMENT}

The presently acceptable mortality for intracardiac repair of the tetralogy of Fallot is related to many factors. Certainly improved anaesthetic and post-operative management, and more physiological conduct of the perfusion have contributed significantly. Most important is the technical skill in securing a total haemodynamic correction. The risk of total repair has been virtually eliminated in the atypical, acyanotic tetralogy. Surgical mortality exists almost exclusively in patients with more severe pathophysiological defects.

There has been considerable discussion concerning the role of palliative procedures and their influence upon subsequent total correction. This question is pertinent not only to the mortality of total repair but to the proper timing of the repair. We have been disturbed by the higher mortality from total correction, reported herein, after a previously constructed systemic-pulmonary artery shunt. Other surgeons have reported that the presence of a prior shunt has not influenced the mortality of subsequent repair (Malm et al., 1964, 1966; Meyer et al., 1967). Kirklin states there is an enhanced mortality in those patients in whom a Potts' shunt had been created or in whom a Blalock shunt had failed (Kirklin et al., 1965). We have attributed this high mortality to an anatomically more severe intracardiac defect, resulting in early disability, thereby necessitating palliation. We have not created shunts solely for polycythaemia and cyanosis nor to "prepare" the pulmonary vascular bed or the underdeveloped left ventricle. Shunt anastomoses have only been performed in severely symptomatic infants and children who would otherwise die of hypoxia. In patients with a non-functioning shunt, the problems of adhesions, the marked collateral mediastinal vascular bed, and the recrudescence of cyanosis and polycythaemia have contributed to operative and post-operative haemorrhage. None the less, Ebert and Sabiston (1967) have recently reported a lower mortality from subsequent total correction in patients with a prior Blalock shunt, despite the usually more severe intracardiac defect and cyanosis, and attribute this to better development of the left ventricle.

We have further been impressed with the effect of a long-standing shunt on the morphology of the heart in the older child coming to total correction. The massive hypertrophy of the right ventricle is accompanied by a virtual collapse of the outflow tract resulting in only a probe-patent orifice in many instances. This has obvious implications regarding outflow reconstructions. This acquired atresia and its influence on total correction has been previously documented (Sabiston et al., 1964). In a smaller number of our patients, inadvertent tears with haemorrhage, inadequate ligation with a residual shunt, or the interval development of pulmonary hypertension have added to the mortality of total correction.

The risks of palliative surgery in symptomatic infants and children are negligible and the results are gratifying, contrasted with the high mortality of total correction in this age-group. The risk of total repair resides primarily in the difficulties of perfusion and adequate intracardiac exposure, and most centres defer total correction for tetralogy of Fallot until 5 to 6 years of age. However, the recent successful total intracardiac correction in an infant with transposition of the great vessels, utilising surface cooling and circulatory arrest, is stimulating (Dillard et al., 1967). McMillan, Johnson, and Machell (1965) have reported 11 survivors of 14 infants and children from 10 months to 4 years and 7 months of age in whom total correction of the tetralogy was performed under conditions of deep hypothermic circulatory arrest achieved with the pump-oxygenator (modified Drew technique). Similarly, Dobell and Charrett (1967) have reported on successful, primary intracardiac repair of symptomatic infants and children with tetralogy of Fallot. Our own continued success with perfusion in younger children, combined with such encouraging reports, makes us willing to attempt primary repair on 3-to-5-year-old children. Unfortunately, the great majority of patients we see are symptomatic infants and children between 0 and 2 years, and it is difficult to deny them the low risk and dramatic improvement afforded by a palliative shunt.

Inherent to our argument that operative mortality is related primarily to the severity of the anatomical defect and the technical skill in correcting this, is the problem of outflow reconstruction. Despite a constant effort to avoid the use of such patches, we often find it impossible to lower significantly the outflow gradient without the use of an enlarging gusset. We will accept a residual gradient of 30$40 \mathrm{~mm}$. $\mathrm{Hg}$ after infundibular resection. However, in many patients with virtual atresia of the infundibular chamber (especially that acquired in association with a long-patent systemic-pulmonary artery shunt) or extreme hypoplasia of the pulmonary valve ring, an outflow reconstruction becomes mandatory. Furthermore, in many instances of marked aortic override, infundibular resection is often limited by the proximity of the aortic sinuses and the need to preserve the crista supraventricularis 
for closure of the ventricular septal defect, emphasizing the need for an enlarging roof. If the valve ring is small, but will accept a $15 \mathrm{~mm}$. sound (in a 10-to-12-year-old child) reconstruction of a hypoplastic pulmonary artery up to the ring, and outflow patching to the ring, is preferable to crossing the pulmonary valve orifice. Post-operative haemodynamic studies have demonstrated normal responses to exercise, despite residual pulmonary insufficiency (Shah and Kidd, 1966; Malm et al., 1966). None the less, such extensive reconstructions have been implicated in the post-operative low cardiac output state, and we and others (Kirklin et al., 1965) have noted a higher mortality when it is necessary to patch across the pulmonary valve annulus. Perhaps the benefits to be derived from the Brock procedure would lie in the development of the right ventricular outflow tract, thus obviating a patch at later correction (Brock, 1957).

As a result of this experience, we have evolved a plan of management for the tetralogy of Fallot.

(1) The acyanotic tetralogy.-This child should undergo elective total correction at 6 to 8 years of age, at a time when such patients usually become symptomatic.

(2) The cyanotic tetralogy. - These children require shunting procedure early in life if it appears that they would not otherwise survive to 5 to 6 years of age, the currently acceptable age of elective total correction. Below the age of 6 months, we prefer the intrapericardial ascending aorta to right main pulmonary artery anastomosis described by Waterston and others (Waterston, 1962; Edwards, Mohtashemi, and Holdefer, 1966; Cooley and Hallman, 1966). From 6 months to 5 years of age we perform a Blalock-Taussig shunt on the side of the innominate artery. We have not created superior vena cava-right main pulmonary artery anastomoses (Glenn procedure) for patients with tetralogy of Fallot.

With this philosophy of management we have been able to salvage and give palliative treatment to children with severe pathophysiological defects who later present for total correction. We attempt to obtain this correction before they outgrow the benefits of the shunt or before the shunt has failed, with subsequent return of cyanosis and polycythaemia. We have further attempted to avoid bilateral palliative procedures. Those patients with severe hypoplasia or atresia of the outflow tract often require partial or total reconstruction with a pericardial roof. If such a patch must cross the valve annulus, a homograft aortic or pulmonary valve should be inserted (Ross and Somerville, 1966). We have performed this in three instances (not in the present series) and have been satisfied with the competence of the valve and the wide outflow tract so obtained.

\section{SUMMARY}

Total haemodynamic correction of the tetralogy of Fallot can now be achieved with acceptable risk. This paper presents 188 children operated upon over the 10-year period between 1957-1966 at the Hospital for Sick Children, Toronto, Canada. The current mortality rate for acyanotic patients is nil and for cyanotics 13-14 per cent.

These gratifying results have evolved from more physiological conduct of perfusions, control of bleeding, better post-operative care, and, most important, increasing surgical skill in the closure of the ventricular septal defect and reconstruction of the outflow path.

We have found that the highest mortality occurs in the older child with a previously constructed shunting procedure that has failed or is inadequate, combined with virtual atresia of the right ventricular infundibulum.

For desperately ill, cyanotic infants under 6 months of age we perform an anastomosis between the ascending aorta and right main pulmonary artery. For symptomatic children up to 5 years of age we create a subclavian-pulmonary artery shunt on the side of the innominate artery. Subsequent total corrections should be performed before failure of the shunt or the return of cyanosis and polycythaemia. Initial total correction may be done on acyanotic children when they become symptomatic at 6 to 8 years of age, and on cyanotic children over 5 years. We are encouraged by reports of total correction in younger children, and agree that this represents the next logical phase of surgery for tetralogy of Fallot.

Total correction is performed using the discoxygenator at $25^{\circ} \mathrm{C}$. core temperature to allow for reduced flow rates and intermittent aortic occlusion. The ventricular septal defect is closed with a patch of woven Dacron. The right ventricular outflow tract is enlarged by sharp resection or a roof of pericardium. All attempts are made to avoid dividing the pulmonary valve annulus by accepting residual gradients of $30-40 \mathrm{~mm}$. $\mathrm{Hg}$, inserting separate gussets in the infundibulum and main pulmonary artery if necessary, or lately, inserting a homograft valve.

\section{REFERENCES}

Blalock, A., and Taussig, H. B. (1945). The surgical treatment of malformations of the heart in which there is pulmonary stenosis or pulmonary atresia. $f$. Amer. med. Ass., 128, 189. 
Brock, R. C. (1957). The Anatomy of Congenital Pulmonary Stenosis. Cassell, London.

- , and Campbell, M. (1950). Infundibular resection or dilatation for infundibular stenosis. Brit. Heart f., $12,403$.

Cooley, D. A., and Hallman, G. L. (1966). Intrapericardial aortic-right pulmonary arterial anastamosis. Surg. Gynec. Obstet., $122,1084$.

Dillard, D. H., Mohri, H., Hessel, E. A., Anderson, H. N., Nelson, R. J., Crawford, E. W., Morgan, B. C., Winterscheid, L. C., and Merendino, K. A. (1967). Correction of total anomalous pulmonary venous drainage in infancy utilizing deep hypothermia with total circulatory arrest. Circulation, 35, Suppl. No. 1, p. 105.

Dobell, A. R. C., and Charrett, E. J. P. (1967). Correction of the younger tetralogy. Presented at the American Association for Thoracic Surgery, 47th Annual Meeting, April 17-19, New York, N.Y.

Ebert, P. A., and Sabiston, D. C. (1967). Surgical management of the tetralogy of Fallot: Influence of a previous systemic-pulmonary anastomosis on the results of open correction. Ann. Surg., 165, 806.

Edwards, W. S., Mohtashemi, M., and Holdefer, W. F. (1966). Ascending aorta to right pulmonary artery shunt for infants with tetralogy of Fallot. Surgery, $59,316$.

Gerbode, F., Osborn, J. J., Kerth, W. J., and O'Brien, M. F. (1964). Complete correction of tetralogy of Fallot. West f. Surg., 72, 1.

Kirklin, J. W., Payne, W. S., Theye, R. A., and DuShane, J. W. (1960). Factors affecting survival after open operation for tetralogy of Fallot. Ann. Surg., 152, 485.

-, Wallace, R. B., McGoon, D. C., and DuShane, J. W. (1965). Early and late results after intracardiac repair of tetralogy of Fallot. 5-year review of 337 patients. Ann. Surg., 162, 578.

Lillehei, C. W., Cohen, M., Warden, H. E., and Varco, R. L. (1955). The direct-vision intracardiac correction of congenital anomalies by controlled cross circulation: Results in 32 patients with ventricular septal defects, tetralogy of Fallot, and atrioventricularis communis defects. Surgery, 38, 11.
McMillan, I. K. R., Johnson, A. M., and Machell, E. S. (1965). Total correction of tetralogy of Fallot in young children. Brit. med. F., 1, 348.

Malm, J. R., Blumenthal, S., Bowman, F. O., Ellis, K., Jameson, A. G., Jesse, M. J., and Yeoh, C. B. (1966). Factors that modify hemodynamic results in total correction of tetralogy of Fallot. $\mathcal{F}$. thorac. cardiovasc. Surg., 52, 502.

—, Bowman, F. O., Jameson, A. G., Ellis, K., and Blumenthal, S. (1964). Current concepts in treatment of tetralogy of Fallot. Dis. Chest, 45, 86.

Meyer, B. W., Lindesmith, G. C., Stanton, R. E., and Jones, J. C. (1967). Surgical correction of tetralogy of Fallot with previous systemic to pulmonary artery shunts. Circulation, 35, Suppl. No. 1, p. 119.

Mustard, W. T., and Thomson, J. A. (1957). Clinical experience with the artificial heart lung preparation. Canad. med. Ass. F., 76, 4.

Potts, W. J., Smith, S., and Gibson, S. (1946). Anastomosis of the aorta to a pulmonary artery; certain types in congenital heart disease. F. Amer. med. Ass., 132, 627.

Ross, D. N., and Somerville, J. (1966). Correction of pulmonary atresia with a homograft aortic valve. Lancet, $2,1446$.

Sabiston, D. C., Cornell, W. P., Criley, J. M., Neill, C. A., Ross, R. S., and Bahnson, H. T. (1964). The diagnosis and surgical correction of total obstruction of the right ventricle: An acquired condition dev́eloping after systemic artery-pulmonary artery anastomosis for tetralogy of Fallot. F. thorac. cardiovasc. Surg., 48, 577.

Scott, H. W., Collins, H. A., and Foster, J. H. (1954). Hypothermia as an adjunct in cardiovascular surgery: Experimental and clinical observations. Amer. Surgn, 20, 799.

Shah, P., and Kidd, L. (1966). Hemodynamic response to exercise and to isoproteronol following total correction of Fallot's tetralogy. F. thorac. cardiovasc. Surg., 52, 138.

Waterston, D. (1962). The treatment of Fallot's tetralogy in infants under the age of one year. Rozhledy $v$ Chirurgii, 41:3, 181 . 